\title{
An in vivo comparison of a catheter mounted pressure transducer system with conventional balloon catheters
}

\author{
I.M. Stell*, S. Tompkins ${ }^{+}$, A.T. Lovell ${ }^{+}$, J.C. Goldstone ${ }^{+}, J^{\prime}$ Moxham ${ }^{\#}$
}

\begin{abstract}
An in vivo comparison of a catheter mounted pressure transducer system with conventional balloon catheters. I.M. Stell, S. Tompkins, A.T. Lovell, J.C. Goldstone, J. Moxham. (C)ERS Journals Ltd 1999.

ABSTRACT: In the assessment of respiratory muscle function balloon catheters have been widely used for pressure measurements. However, this type of investigation is poorly tolerated by acutely ill patients. This study assessed the performance of a possible alternative, a catheter-mounted miniature pressure transducer (CMT).

The assessment consisted of a laboratory study of the linearity, frequency response, and stability of gain and baseline of the CMT system, and an in vivo study directly comparing the CMT and balloon catheter systems in seven normal subjects for a range of respiratory manoeuvres. These were: 1 ) maximal inspiratory and expiratory pressures against a closed airway, 2) twitch transdiaphragmatic pressure elicited by cervical magnetic phrenic nerve stimulation, and 3) tidal breathing, sniffs and coughs in five body positions. The agreement of the two systems was analysed for measurements of 1) absolute pressures, 2) magnitude of changes in pressure, and 3) rate of change of pressure (maximum relaxation rate after sniff manoeuvres).

The CMT system was linear, with a high frequency response and stable gain, but showed baseline drift. The two systems agreed well for measurements of change and rate of change of pressure, but less well for measurements of absolute pressure.

The CMT system tested is potentially useful for studies of acute changes in respiratory pressures, or studies of respiratory muscle strength, but would be less useful where accurate measurements of absolute pressures are required. Eur Respir J 1999; 13: 1158-1163.
\end{abstract}

For accurate assessment of respiratory muscle function it is sometimes useful to measure oesophageal ( $\left.P_{\mathrm{oes}}\right)$, gastric $(P$ ga $)$ and transdiaphragmatic $(P$ di $)$ pressures [1]. The conventional method for making these measurements, with balloon catheters, is uncomfortable, and not tolerated by some patients. In particular, these measurements can seldom be performed in acutely breathless or ill patients [2]. There is a need for an alternative method that is more easily tolerated. One possibility is to replace the conventional pair of balloon catheters by a single catheter which has small integral pressure transducers. The potential advantages would be one slim catheter instead of two bulky ones and a catheter that can be softer and more flexible, because the catheter is not required to have a lumen. Such catheters have been available for some time; however, concern related to the overestimation of $P$ oes from early work in infants [3] has prevented widespread adoption of the catheter mounted miniature pressure transducers (CMTs) for this patient group [4], and may have discouraged their use in adults. Studies of lung elastance [5] and sniff $P$ di [6] in adults have shown CMTs to be well tolerated and to give measurements comparable to those obtained with balloon catheters. Validation of CMTs by comparison with balloon catheters for a range of respiratory manoeuvres has not been reported. The purpose of this study was to compare CMTs to conventional balloon catheters during the range of manoeuvres used to assess respiratory muscle function.
*Accident \& Emergency Dept and ${ }^{\#}$ Dept of Respiratory Medicine, King's College Hospital, London, UK. ${ }^{+}$Dept of Anaesthetics, Middlesex Hospital, London, UK.

Correspondence: I.M. Stell

Accident \& Emergency Dept

Bromley Hospital Cromwell Avenue

Bromley Hospitals NHS Trust Kent BR2 9AJ

UK

Fax: 441812897032

Keywords: Balloon catheters catheter-mounted transducers gastric pressure

oesophageal pressure

respiratory muscles

Received: July 151998

Accepted after revision November 301998
Subjects and methods

\section{Equipment}

The CMT used in this study was of $120 \mathrm{~cm}$ length, 2.1 $\mathrm{mm}$ external diameter, with two integral transducers, each measuring $5 \mathrm{~mm}$ long by $2 \mathrm{~mm}$ wide, mounted 5 and 35 $\mathrm{cm}$ from the distal tip (Gaeltec, Dunvegan, Isle of Skye, UK). The output from each transducer was amplified using a two-channel amplifier (Gaeltec S7b/2). This amplifier has centre-zero galvanometers displaying the output for each channel.

The balloon catheters consisted of $10 \mathrm{~cm}$ latex balloons, wall thickness $\sim 0.085 \mathrm{~mm}$, balloon circumference $2 \mathrm{~cm}$ (deflated), mounted on $110 \mathrm{~cm}$ long polyethylene catheters of $1.0 \mathrm{~mm}$ internal diameter (Morgan Medical, Rainham, Kent, UK). These were connected to differential pressure transducers, one side of which were open to atmospheric pressure, with an operating range of $\pm 300 \mathrm{cmH}_{2} \mathrm{O}$ (Precision Medical, Leeds, UK).

Calibration of the CMT was performed by placing the catheter within a sealed, air-filled calibration chamber, within which positive and negative pressures were generated by an attached, air-filled syringe. The chamber was connected to a water manometer as a reference, and twopoint calibration performed by recording the voltage output of each of the two channels of the CMT system during exposure to the reference positive and negative pressures. 
Calibration of the pressure transducers connected to the balloon catheters was also performed using a water manometer as a reference, and with positive and negative pressures generated by an air-filled syringe. The calibration procedures were repeated at the beginning of each laboratory session. The outputs from both the CMT and balloon catheter systems were acquired via an analogue-to-digital convertor to a laboratory software package (Labview 2.2, National Instruments, Austin, TX, USA), installed on a desk-top computer (Macintosh Centris 650). Data were sampled at rates between 0.1 and $1,000 \mathrm{~Hz}$, as required for different parts of the study.

\section{In vitro study of CMT system}

The linearity of the amplifier outputs was tested by recording the outputs for $10 \mathrm{cmH}_{2} \mathrm{O}$ incremental steps of pressure between 0-200 $\mathrm{cmH}_{2} \mathrm{O}$ with the CMT immersed in a water manometer.

The frequency response of the catheters was tested by recording the time taken for the recorded pressure to change from 10 to $90 \%$ of its new value when exposed to a square-wave pressure change. This was carried out by inserting the distal of the two transducers, sampling pressure at a frequency of $1,000 \mathrm{~Hz}$, into a balloon which was inflated to $100 \mathrm{cmH}_{2} \mathrm{O}$, and then burst with a scalpel blade. This manoeuvre was assumed to cause an instantaneous pressure drop and the frequency response was the time taken for the recorded pressure to fall between 90 and 10 $\mathrm{cmH}_{2} \mathrm{O}$ [8].

The stability of the gain and baseline were investigated by two methods.

First method. The outputs of the two channels of the CMT amplifier were recorded during repeated exposure of the CMT to the same two set pressures at hourly intervals. For this part of the study the amplifier outputs were read directly from the amplifier galvanometers. At hourly intervals, the CMT catheter was placed within the calibration chamber which was connected to a water manometer, and recordings were made with the chamber pressure set at both 0 and $40 \mathrm{cmH}_{2} \mathrm{O}$ by means of an attached syringe. Between the recordings, the catheter was immersed in a water bath at $37^{\circ} \mathrm{C}$. In this way, any baseline drift over time in the output for either channel, and any change in the voltage increment produced by the $40 \mathrm{cmH}_{2} \mathrm{O}$ increase in pressure could be quantified. An additional CMT and amplifier were used, and this procedure repeated with each CMT connected to each amplifier in turn, to cheek whether the stability of gain and baseline varied between transducer/amplifier combinations. These procedures were repeated after allowing the CMT catheter to dry in air for varying periods from a few hours to three weeks, and with differing amplifier gain settings, to assess the effects of these changes on the stability of the baseline and gain.

Second method. This investigation of baseline drift was designed to assess whether the rate and degree of any drift followed a predictable pattern. This was investigated by assessing the drift during continuous recordings made from each of the transducers while they were maintained at fixed pressures. A range of stable, positive and negative pressures for this were provided within a $100 \mathrm{~cm}$ length of water-filled tubing. This was suspended, in a "J" shape, with the upper end sealed, and the lower end open to the atmosphere. The CMT catheter was passed along this tubing and the transducers were positioned at specified pressures by measuring and adjusting the vertical distances from the transducers to the water meniscus at the open end of the tubing. The transducers were maintained in the same positions for $6 \mathrm{~h}$, and the output of the CMT amplifier was recorded continuously, with sampling every $10 \mathrm{~s}$. This procedure was repeated with the transducers positioned at a range of pressures between -15 and $+15 \mathrm{cmH}_{2} \mathrm{O}$, in $5 \mathrm{cmH}_{2} \mathrm{O}$ incremental steps.

\section{In vivo study}

In seven normal subjects, two balloon catheters were passed through one nostril and the CMT through the other. Both balloon catheters were advanced until their distal tips were $70 \mathrm{~cm}$ from the nares and within the stomach. One was withdrawn by $30 \mathrm{~cm}$ to lie in the mid-oesophagus, to record $P_{\text {oes }}$ [9]. The remaining catheter within the stomach recorded $P$ ga. The oesophageal and gastric balloons were filled with $0.5 \mathrm{~mL}$ and $2.0 \mathrm{~mL}$ of air, respectively, and these volumes were checked periodically throughout the studies. The CMT catheter was advanced so that the transducers were at 65 and $35 \mathrm{~cm}$ from the nares, corresponding to the midpoints of each balloon. The correct positions of the oesophageal balloon and the proximal transducer of the CMT were checked by the Baydur manoeuvre [10] and adjustments made as necessary.

Pressure recordings were made with each subject performing a number of respiratory manoeuvres. These were 1) maximum static inspiratory $(P \mathrm{I}, \mathrm{max})$ and expiratory $(P$ E,max $)$ pressures in the sitting position $[11,12], 2) P$ di changes elicited by single cervical magnetic stimulations (CMS) of the phrenic nerves (twitch Pdi) [13], and 3) tidal breathing, sniffs of varying intensities [14] and coughs of varying intensities [15], in each of five body positions sitting, semi-recumbent, supine, and right and left lateral positions.

Pressures were analysed for three $P \mathrm{I}$,max and $P$ E,max manoeuvres, five tidal breaths in each position, sniffs and coughs (six sniffs for maximum relaxation rate), 10 and eight CMS stimulations. Sniffs, coughs and CMS stimulations were at functional residual capacity (FRC), $P \mathrm{I}$,max at residual volume (RV) and $P$ E,max at total lung capacity (TLC). Recordings affected by oesophageal peristaltic waves were discounted. The following pressures, pressure changes and rates of pressure change, recorded simultaneously by the two systems, were used in the analysis: 1) the absolute pressure (relative to atmospheric) recorded at baseline and peak pressure for each manoeuvre, 2) the changes in $P$ oes generated by $P \mathrm{I}$,max and $P$ E,max manoeuvres, 3) changes in $P$ di during tidal breathing, sniffs and CMS, 4) the changes in $P_{\text {oes }}$ and $P$ ga generated by coughs, and 5 ) the maximum relaxation rate (MRR) (\% pressure fall.10 $\mathrm{ms}^{-1}$ ) of Poes for sniffs in the sitting position [16]. Sniffs selected for MRR analysis had: 1) peak negative pressures $50-90 \%$ of the maximum recorded for that subject, 2) were of $<500 \mathrm{~ms}$ duration, 3) peak pressure 
was maintained for $<50 \mathrm{~ms}$, and 4) had pressure waveforms displaying smooth upstroke and decay curves [17].

The $P$ oes recording was noted to be particularly affected by cardiac contraction in some body positions. The magnitude of this cardiac artefact was calculated by measuring the maximum pressure change from the baseline, corresponding to the heartbeat, for each subject during tidal breathing in the supine position.

The agreement between the CMT and balloon catheters was assessed by the method of Bland and Altman [18]. Two figures were calculated, the bias of CMT compared to balloon catheters and the limits of agreement for the two methods. The study protocol was approved by the local research ethics committee

\section{Results}

\section{CMT: linearity, frequency response and stability of gain and baseline}

The output of the CMT with its amplifier was linear across the pressure range tested. The frequency response of the transducer was between 250 and $333 \mathrm{~Hz}$. The baseline of the CMT drifted with time. The maximum drift recorded was the equivalent of a pressure change of $30 \mathrm{cmH}_{2} \mathrm{O}$ over $2 \mathrm{~h}$. Drift could be in either a positive or negative direction, was not linear, and most of the drift occurred during the first hour of use. The extent of this drift varied with different transducer/amplifier combinations, and also with how long the CMT had been allowed to dry. The drift was least if the catheter was used daily, and increased greatly if the catheter was allowed to dry for several weeks. If the catheter had been dry for some time, the extent of drift could be reduced by soaking it in water for an hour before use. The baseline drift was also reduced by lower amplifier gain settings. With these measures the drift could be reduced to $<3 \mathrm{cmH}_{2} \mathrm{O}$ in the first hour, but the rate and extent of drift could not be predicted. Continuous baseline recordings, under optimal conditions for stability, are shown in figure 1 , at a range of constant pressures. The gain remained stable over time for all the transducer/ amplifier combinations

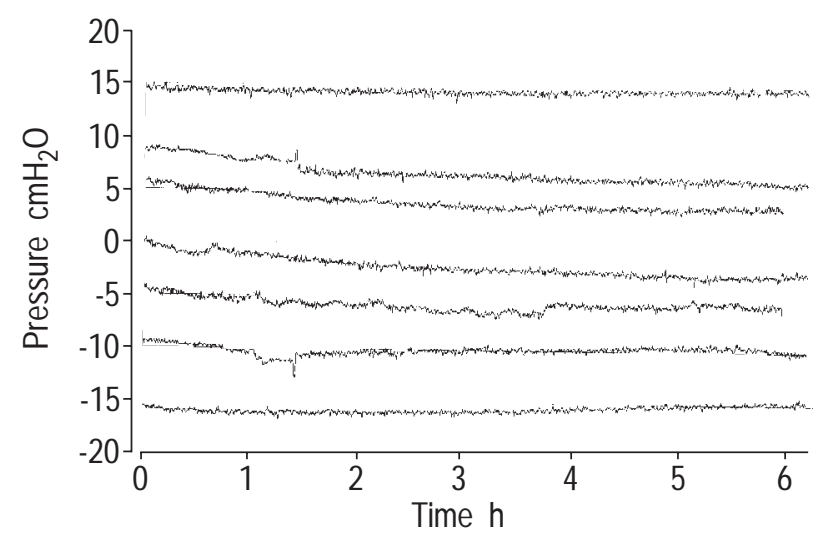

Fig. 1. - Drift of the catheter-mounted miniature pressure transducer baseline over $6 \mathrm{~h}$ while exposed to constant pressures in the range -15$+15 \mathrm{cmH}_{2} \mathrm{O}$

\section{In vivo study}

All seven subjects found the CMT easier to swallow than the balloon catheters, and more comfortable during use. However, whereas the rigidity of the catheters allowed the investigator to assist the passage of the balloon catheters through the pharynx, the greater flexibility of the CMT necessitated active swallowing by each subject.

Figure 2 shows representative tracings of the balloon catheter and CMT recordings of pressure during sniffs in the sitting position for one subject. The agreement for the two methods for absolute pressure are shown in figure 3 for $P$ ga, and $P$ oes. These two figures compare directly all pairs of measurements recorded by the two systems. For both $P_{\text {ga }}$ and $P_{\text {oes, }}$, the pressures recorded by the balloon catheter system were, on average greater than those recorded by the CMT, the mean differences being 4.3 and $7.2 \mathrm{cmH}_{2} \mathrm{O}$, respectively. This difference between the pressures recorded by the two systems remained the same across the range of $P$ ga measurements, from -15 to +180 $\mathrm{cmH}_{2} \mathrm{O}$; and $P$ oes measurements from -100 to $+180 \mathrm{~cm}-$ $\mathrm{H}_{2} \mathrm{O}$.

The agreement for the two methods for manoeuvres in the sitting position, are shown in figure 4 for $P_{\text {oes }}$ during $P \mathrm{I}$,max $\left(P \mathrm{I}, \max P_{\mathrm{oes}}\right)$ and $P$ E,max manoeuvres $(P \mathrm{E}, \max P$ oes $)$, twitch $P$ di for CMS, $P$ di during tidal breaths, sniff $P$ di, cough $P$ oes and MRR. These measurements of pressure changes by the two systems agree more than measurements of absolute pressure. The differences (bias) between the measurements of the two systems were close to zero (table 1 ), except for the more rapidly changing pressure signals such as sniffs and CMS, where the CMT system recorded larger pressure changes.

The bias and limits of agreement for the two methods for all manoeuvres in all positions are shown in table 1 . The mean \pm SD amplitude of the cardiac artefact in the supine position measured by the CMT system was $5.47 \pm 5.1$ $\mathrm{cmH}_{2} \mathrm{O}$, compared to the corresponding measurements with the balloon catheters of $2.15 \pm 1.3 \mathrm{cmH}_{2} \mathrm{O}$.

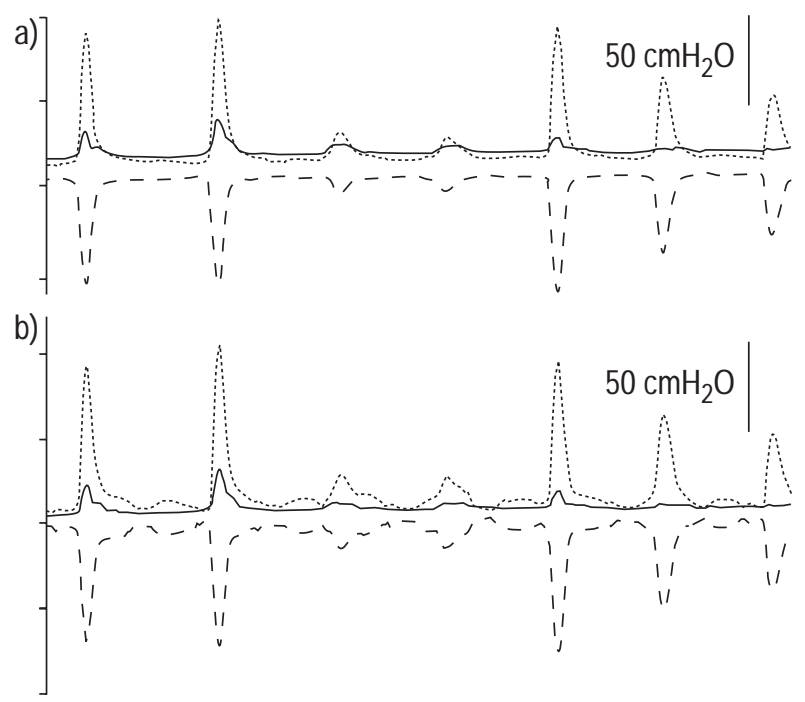

Fig. 2. - Oesophageal $(---)$ and gastric (-) pressures recorded simultaneously with the balloon catheters (a) and the catheter-mounted miniature pressure transducer system (b) during sniffs of varying intensities. - - - : transdiaphragmatic pressure. 
a)

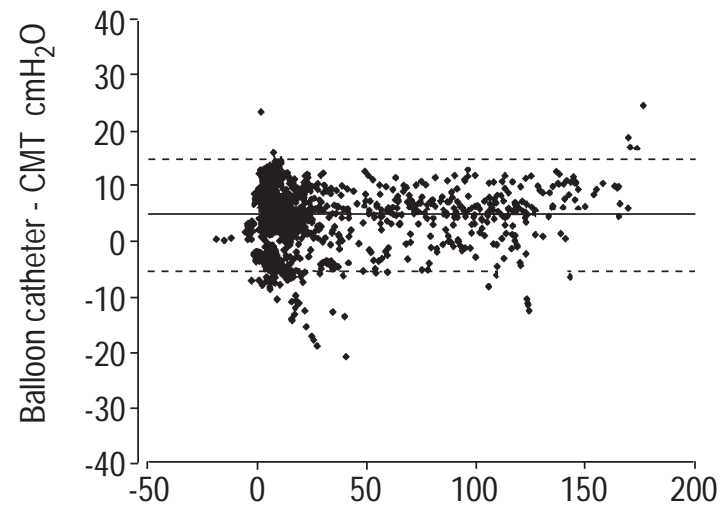

b)

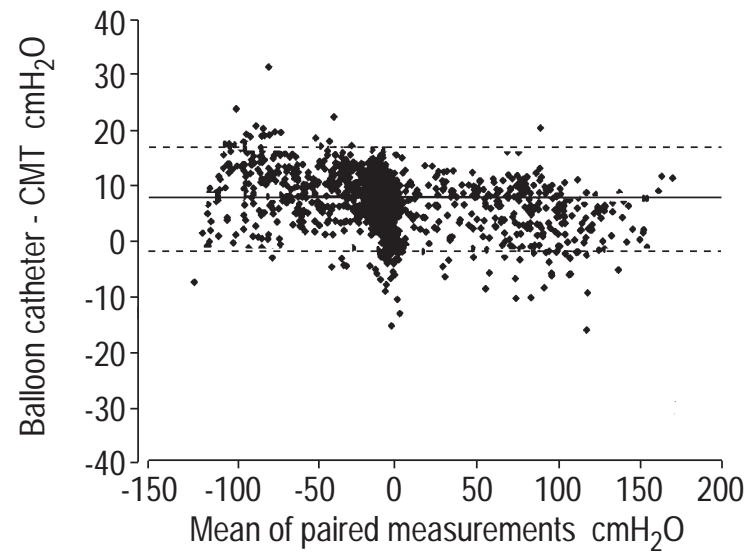

Fig. 3. - Bland and Altman plots comparing the agreement of measurements of absolute pressure by the catheter-mounted miniature pressure transducer (CMT) and balloon catheter systems for: a) gastric pressure and b) oesophageal pressure. Results are for seven subjects, with 1,769 pairs of measurements. Differences between paired measurements on vertical axis, and means of pairs on horizontal axis. mean difference, or bias; - - - - : limits of agreement ( $\pm 2 \mathrm{SD})$.

\section{Discussion}

The CMT investigated in this study gave very similar results for changes in $P_{\text {oes }}$ and $P$ ga during the range of manoeuvres used in assessing respiratory muscle strength, to those provided by conventional balloon catheter systems. They were also more easily tolerated than balloon catheters, as has been reported previously $[2,5]$.
In estimating absolute pressures the limits of agreement for CMT were wide compared to balloon catheters. Explanations for this include the following. 1) The 10 $\mathrm{cm}$ balloons of the balloon catheters are likely to have recorded the most negative pressure occurring along their length, as the contained bubble of air within the balloon will move to the site where the pressure is least. This is in contrast to the CMT system recording from an area of 10 $\mathrm{mm}^{2}$. 2) There may have been hydrostatic pressure differences between the $P$ ga recordings of the two systems due to the air-filled balloon floating on gastric fluid and the CMT tip being immersed. 3) Baseline drift of the CMT pressure recordings. The CMT has the disadvantage that the absolute pressure level cannot be checked with respect to atmospheric pressure during the conduct of a study. Some assessment of the magnitude of drift can be established by re-checking the baseline after removal of the catheter at the end of a study, however as the drift is not linear, this will only allow approximations. Baseline drift has been noted in several studies of CMT systems [2-6]. With the CMT used in the present study, the physical characteristics of the chemical coating of the pressure transducers are affected by prolonged dryness and baseline drift can be reduced by prior soaking. The baseline was also more stable with lower amplifier gain settings, and the manufacturer recommends that the gain be adjusted to give an amplifier output of $1 \mathrm{~V}$ at full scale deflection.

In comparing these measurements made by the CMT system with those made by balloon catheter systems, it should be borne in mind that balloon catheter systems are themselves subject to some inaccuracies in the measurement of $P$ oes pressure, depending on the physical characteristics of the catheters and balloons used [8]. Although $P$ oes is generally a close approximation to pleural pressure, the relationship between these two pressures can vary, particularly in relation to posture and distance from the cardia [10].

\section{Disadvantages of the CMT system}

The main disadvantage of the CMT system is the instability of the baseline. This makes the system unsuitable for

Table 1. - Tabulated results of Bland and Altman analyses for all manoeuvres in all positions. Mean difference between pairs of measurements shown as "bias", and two standard deviations of this difference as "limits of agreement"

\begin{tabular}{|c|c|c|c|c|c|c|c|c|c|c|}
\hline \multirow[b]{2}{*}{ Position } & \multicolumn{5}{|c|}{ Bias (balloon catheters - CMT) } & \multicolumn{5}{|c|}{ Limits of agreement ( $\pm 2 \mathrm{SD}$ ) } \\
\hline & Sitting & $\begin{array}{l}\text { Semi- } \\
\text { recumbent }\end{array}$ & Supine & $\begin{array}{l}\text { Right } \\
\text { lateral }\end{array}$ & $\begin{array}{c}\text { Left } \\
\text { lateral }\end{array}$ & Sitting & $\begin{array}{l}\text { Semi- } \\
\text { recumbent }\end{array}$ & Supine & $\begin{array}{l}\text { Right } \\
\text { lateral }\end{array}$ & $\begin{array}{l}\text { Left } \\
\text { lateral }\end{array}$ \\
\hline Sitting tidal $P$ di $\mathrm{cmH}_{2} \mathrm{O}$ & 0.2 & -0.5 & -0.1 & 0.9 & 0.4 & 1.4 & 6.3 & 5.1 & 5.1 & 3.9 \\
\hline Sitting sniff $\mathrm{Pdi}_{\mathrm{di} \mathrm{C}_{2} \mathrm{O}}$ & -3.6 & -5.2 & -2.7 & -2.8 & -3.2 & 9.0 & 10.2 & 8.8 & 8.4 & 6.9 \\
\hline Sitting cough $P_{\text {ga }} \mathrm{cmH}_{2} \mathrm{O}$ & 1.5 & -0.8 & -0.1 & 0.3 & 0.2 & 7.4 & 8.4 & 3.5 & 5.7 & 5.1 \\
\hline Sitting cough $P_{\text {oes }} \mathrm{cmH}_{2} \mathrm{O}$ & -0.7 & -1.7 & -1.4 & -3.3 & -2.4 & 11.0 & 10.6 & 10.2 & 10.2 & 9.6 \\
\hline$P \mathrm{I}, \max P_{\text {oes }} \mathrm{cmH}_{2} \mathrm{O}$ & -1.5 & & & & & 10.0 & & & & \\
\hline$P$ E,max $P$ oes $\mathrm{cmH}_{2} \mathrm{O}$ & -2.4 & & & & & 8.2 & & & & \\
\hline$P$ di with $\mathrm{CMS} \mathrm{cmH}_{2} \mathrm{O}$ & -2.1 & & & & & 8.4 & & & & \\
\hline $\begin{array}{l}\text { Maximum relaxation rate } \\
\% \text { pressure loss } 10 \mathrm{~ms}^{-1}\end{array}$ & -0.27 & & & & & 0.93 & & & & \\
\hline
\end{tabular}

CMT: catheter-mounted miniature pressure transducer; $P$ di: transdiaphragmatic pressure; $P$ ga: gastric pressure; $P$ oes: oesophageal pressure; $P \mathrm{I}$,max: maximum inspiratory pressure; $P \mathrm{I}$,max $P_{\text {oes: }} P_{\text {oes }}$ during $P \mathrm{I}$,max manoeuvre; $P \mathrm{E}$,max: maximum expiratory pressure; $P$ E,max $P_{\text {oes: }}$ Poes during $P$ E,max manoeuvre; CMS: cervical magnetic stimulation. 

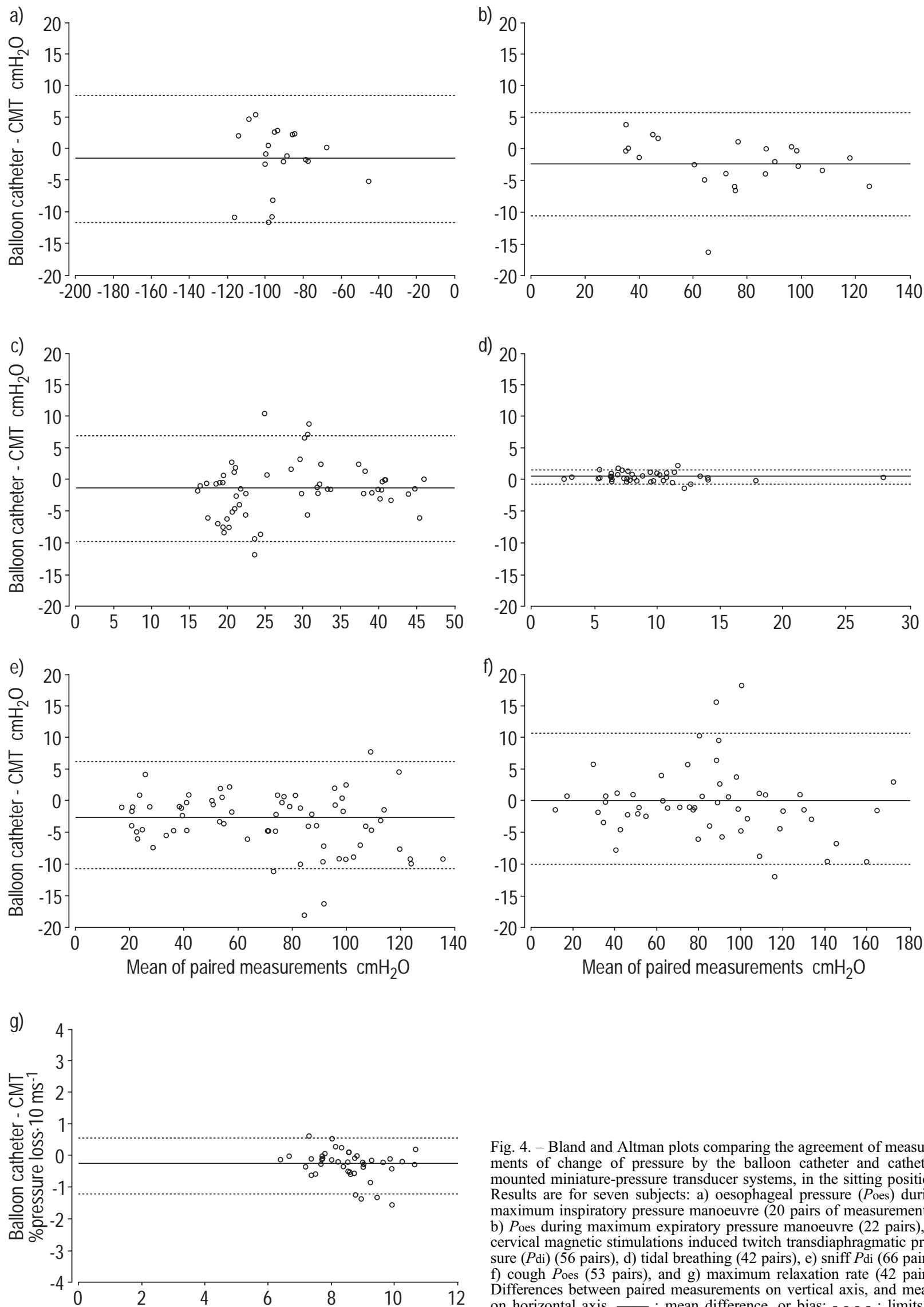

Fig. 4. - Bland and Altman plots comparing the agreement of measurements of change of pressure by the balloon catheter and cathetermounted miniature-pressure transducer systems, in the sitting position. Results are for seven subjects: a) oesophageal pressure $\left(P_{\text {oes }}\right)$ during maximum inspiratory pressure manoeuvre (20 pairs of measurements), b) Poes during maximum expiratory pressure manoeuvre (22 pairs), c) cervical magnetic stimulations induced twitch transdiaphragmatic pressure $(P \mathrm{di})(56$ pairs $)$, d) tidal breathing (42 pairs), e) sniff $P$ di (66 pairs), f) cough $P_{\text {oes }}$ (53 pairs), and g) maximum relaxation rate (42 pairs). Differences between paired measurements on vertical axis, and means

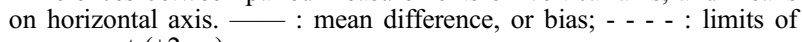
Mean of paired measurements \%pressure loss.10 ms-1 agreeement $( \pm 2 \mathrm{SD})$. 
studies in which absolute pressures need to be accurately measured.

Cardiac artefacts affecting the $P_{\text {oes }}$ recording were noted with both systems, and were most marked in the supine position. But, whereas the magnitude of these was very similar for different subjects when measured with the balloon catheters, they varied considerably when measured by the CMT system. This cardiac artefact is likely to result from direct pressure from overlying mediastinal structures. The variability seen with the CMT system probably arises from variations in the positioning of the small oesophageal transducer with respect to these mediastinal structures. Therefore, particularly in supine subjects, it may be necessary to repeat manoeuvres to obtain recordings unaffected by the cardiac artefact.

The need for active swallowing of the catheter is not a disadvantage in conscious, cooperative patients with normal swallowing mechanisms. However, sedated patients, or those with neuromuscular disease impairing swallowing, would not be able to assist the passage of the catheter. A more rigid catheter would be required in such cases.

\section{Advantages of the CMT system}

The main advantage of the CMT is that it is more comfortable to pass through the nose and swallow, and remains comfortable in use, at least over the few hours required in this study. A small additional advantage is that there is no need to check repeatedly the volume of air in the balloons.

The higher frequency response of the CMT system records rapidly changing pressures more accurately, by avoiding the blunting of pressure changes that arise in an air-filled system because of the compression or rarefaction of air. As a result the recorded pressure changes of coughs, sniffs, CMS, and the rate of change of pressure in MRR studies, tends to be slightly higher. This may mean that normal ranges established with balloon catheters may not be strictly applicable.

One potential advantage of the system, at least in Europe, arises from difficulties in obtaining commercial supplies of balloon catheters as a consequence of changes in laws in the European Union relating to product licensing.

\section{Cost, storage and cleaning}

One CMT with two transducers, of the type used in this study with the appropriate amplifier costs $\sim £ 2,000$ (November 1997). Commercial balloon catheters cost $\sim £ 20$ for a pair. Costs for transducers and amplifiers for balloon catheter systems depend on specifications; typical costs would be $\sim £ 450$ per transducer and $£ 900$ for a multichannel amplifier.

The CMT catheters can be sterilized by soaking with cold sterilization solutions such as glutaraldehyde, and are then stored dry at room temperature. The two catheters used in this study did not deteriorate after six months of use, including $\sim 20$ sterilizations each in glutaraldehyde.

In summary, catheter-mounted miniature pressure transducers are well tolerated, have a rapid response rate and accurately measure pressure changes. However, baseline drift can be a problem and the system is less accurate for the measurement of absolute pressures.

\section{References}

1. Polkey MI, Green M, Moxham J. Measurement of respiratory muscle strength (editorial). Thorax 1995; 50: 1131-1135.

2. Gilbert R, Peppi D, Auchincloss JH. Measurement of transdiaphragmatic pressure with a single gastric-esophageal probe. J Appl Physiol 1979; 47: 628-630.

3. Beardsmore CS, Wong Y-C, Stocks J, Silverman M. Assessment of the catheter tip pressure transducer for use in infant lung function tests. Med Biol Eng Comput 1982; 20: $657-660$.

4. Coates AL, Stocks J. Esophageal pressure manometry in human infants. Pediat Pulmonol 1991; 11: 350-360.

5. Panizza JA, Finucane KE. Comparison of balloon and transducer catheters for estimating lung elasticity. $J \mathrm{Appl}$ Physiol 1992; 72: 231-235.

6. Evans SA, Watson L, Cowley AJ, Johnston IDA, Kinnear WJ. Normal range for transdiaphragmatic pressures during sniffs with catheter mounted transducers. Thorax 1993; 48: 750-753.

7. Lemen R, Benson M, Jones JG. Absolute pressure measurements with hand-dipped and manufactured esophageal balloons. J Appl Physiol 1974; 37: 600-603.

8. Mead J, McIlroy MB, Selverstone NJ, Kriete BC. Measurement of intraesophageal pressure. J Appl Physiol 1955; 7: 491-495.

9. Milic-Emili J, Mead J, Turner JM. Topography of esophageal pressure as a function of posture in man. $J$ Appl Physiol 1964; 19: 212-216.

10. Baydur A, Behrakis PK, Zin WA, Jaeger M, Milic-Emili J. A simple method for assessing the validity of the esophageal balloon technique. Am Rev Respir Dis 1982; 126: 788-791.

11. Black LF, Hyatt RE. Maximal respiratory pressures: normal values and relationship to age and sex. Am Rev Respir Dis 1969; 99: 696-702.

12. Enright PL, Kronmal RA, Manolio TA, Schenker MB, Hyyatt RE. Respiratory muscle strength in the elderly. $A m$ J Respir Crit Care Med 1994; 149: 430-438.

13. Similowski T, Fleury B, Launois S, Cathala HP, Bouche P, Derenne JP. Cervical magnetic stimulation: a new painless method for bilateral phrenic nerve stimulation in conscious humans. J Appl Physiol 1989; 67: 1311-1318.

14. Miller JM, Moxham J, Green M. The maximal sniff in the assessment of diaphragm function in man. Clin Sci 1985; 69: 91-96.

15. Kyroussis D, Polkey MI, Hughes PD, et al. Abdominal muscle strength measured by gastric pressure during maximal cough. Thorax 1996; 51 (Suppl. 3): A45.

16. Esau SA, Bellemare F, Grassino A, Permutt S, Roussos C, Pardy RL. Changes in relaxation rate with diaphragmatic fatigue in humans. $J$ Appl Physiol 1983; 54: 1353-1360.

17. Kyroussis D, Polkey MI, Keilty SE, et al. Exhaustive exercise slows inspiratory muscle relaxation rate in chronic obstructive pulmonary disease. Am J Respir Crit Care Med 1996; 153: 787-793.

18. Bland JM, Altman DG. Statistical methods for assessing agreement between two methods of clinical measurement. Lancet 1986; i: 307-310. 